\title{
Research Paper: The Mediating Role of Cognitive Emotion Regulation Strategies on Mindfulness, Anxiety, and Academic Procrastination in High Schoolers
}

\author{
Sajjad Rezaei' ${ }^{1}$, Azra Zebardast ${ }^{* *}$ (1) \\ 1. Department of Psychology, Faculty of Literature and Humanities, University of Guilan, Rasht, Iran.
}

\begin{tabular}{|c|c|}
\hline \multirow{3}{*}{$\begin{array}{c}\text { Use yur device tocsan } \\
\text { and read the articlo online }\end{array}$} & \\
\hline & $\begin{array}{l}\text { Anxiety, and Academic Procrastination in High Schoolers. Journal of Practice in Clinical Psychology, 9(2), 133-142. https://doi. } \\
\text { org/10.32598/jpcp.9.2.731.1 }\end{array}$ \\
\hline & doi) https://doi.org/10.32598/jpcp.9.2.731.1 \\
\hline
\end{tabular}

(c) (1) (\$)

Article info:

Received: 13 Dec 2020

Accepted: 22 Feb 2021

Available Online: 01 Apr 2021

Keywords:

Procrastination, Anxiety, Mindfulness, Cognitive emotion regulation

\section{ABSTRACT}

Objective: The present study aimed to investigate the mediating role of cognitive emotion regulation strategies on the relationship between mindfulness, anxiety, and procrastination in high school students.

Methods: The study sample consisted of 350 high school female students in Rasht City, Iran. The study subjects responded to the Academic Procrastination Scale (APS), the Cognitive Emotion Regulation Questionnaire (CERQ), the Cattell Anxiety Scale (CAS), and the Five Facet Mindfulness Questionnaire (FFMQ). Data analysis was performed by Pearson productmoment correlation coefficient and structural equation modeling technique in SPSS and AMOS. Bootstrap in Preacher and Hayes' Macro program (2008) was also used to test the indirect relationships between the study variables.

Results: There was a direct and significant relationship between academic procrastination, anxiety, and maladaptive cognitive emotion regulation strategies $(\mathrm{P}<0.0001)$. There was an inverse and significant relationship between procrastination, adaptive cognitive emotion regulation strategies, and mindfulness $(\mathrm{P}<0.0001)$. Mediation analysis data revealed that the maladaptive cognitive emotion regulation strategies exacerbated the effects of anxiety on academic procrastination; the indirect effect of anxiety on procrastination through adaptive strategies was significant.

Conclusion: Procrastination in students could be reduced by minimizing anxiety, correcting maladaptive cognitive emotion regulation strategies, and strengthening adaptive cognitive emotion regulation strategies. Anxiety may aggravate academic procrastination by generating maladaptive mechanisms.

\section{"Corresponding Author:}

Azra Zebardast, PhD.

Address: Department of Psychology, Faculty of Literature and Humanities, University of Guilan, Rasht, Iran.

Tel: +98 (13) 33690274

E-mail: zebardast@guilan.ac.ir 


\section{Highlights}

- Procrastination can be decreased by minimizing anxiety, correcting maladaptive cognitive emotion regulations and reinforcing adaptive cognitive emotion regulation strategies.

- Anxiety can exacerbate academic procrastination by producing maladaptive procedures.

\section{Plain Language Summary}

The study aimed to investigate the mediating role of cognitive emotion regulation strategies on the relationship between mindfulness, anxiety, and procrastination in high school students. The study sample consisted of 350 high school female students in Rasht City, Iran. The subjects responded to the various questionnaires. Results demonstrated that There was a direct and significant relationship between academic procrastination, anxiety, and maladaptive cognitive emotion regulation strategies. There was an inverse and significant relationship between procrastination, adaptive cognitive emotion regulation strategies, and mindfulness. Mediation analysis data revealed that the maladaptive cognitive emotion regulation strategies exacerbated the effects of anxiety on academic procrastination; the indirect effect of anxiety on procrastination through adaptive strategies was significant. Procrastination in students could be reduced by minimizing anxiety, correcting maladaptive cognitive emotion regulation strategies, and strengthening adaptive cognitive emotion regulation strategies. Anxiety may aggravate academic procrastination by generating maladaptive mechanisms.

\section{Introduction}

espite advances in novel and effective training methods, educators and researchers are focused on the increasing rate of academic noncompliance due to Academic Procrastination (AP) at most educational levels (Krispenz, Gort, Schültke \& Dickhäuser, 2019).

Postponing the start or end of academic homework to the future for irrational reasons, namely AP, continues as long as the individual feels uncomfortable and creates a significant gap between their intention and action. This matter is among the major reasons for academic failure (Young, 2010).

According to Ferrari (2000), the causes of procrastination are classified into 3 categories. First, the emotions class under which individuals succeed in timeconstrained situations and interpret such conditions as challenging and exciting. Second, avoiders who leave things because of their low self-efficacy to reduce anxiety. Third, decisional procrastinators who are unable to make decisions at a specific timeframe and procrastinate due to their limited decision-making skill.

Procrastination factors are situational and personal. A high volume of homework and inappropriate time management are among the major situational factors in students' procrastination (Hussain \& Sultan, 2010); fear of failure, depression, and anxiety are among the relevant personal factors (Chang, 2014).

All results signifying that anxiety is associated with procrastination are addressed as antecedents and outcomes (Chang, 2014). Anxiety is directly related to procrastination, which provides a detrimental effect on students' mental health and academic performance; such an impact is created by negative cognitive evaluation and severe physiological reactions (Afshari \& Hashemi, 2019). According to prior research results, $25 \%-40 \%$ of learners in state-run training centers experience anxiety (Putwain \& Daniels, 2010). Students with anxiety experience unpleasant moods, physiological arousals, and anxious thoughts (Pekran, Frenzel, Goetz \& Perry, 2006); therefore, they tend to leave the situation and are more prone to present procrastination. However, this result was stated by studies that have examined the relationship between anxiety and procrastination at a specific period (Krispenz et al., 2019). Longitudinal studies suggested complex causal relationships between anxiety and procrastination (Pekrun, Ferenzel, Goetz \& Perry, 2007).

The appraisal-anxiety-avoidance model proposed by Lazarus and Fulker (1984) claims that individuals, because of the risk assessment of the situation and their inability to cope with it, become procrastinate to avoid the conditions. Contrarily, the Temporal Motivation Theory (TMT) states that procrastination is not always a compulsory consequence of anxiety. Procrastination is also prevalent in students who have enough time to take the 
exam at the beginning of the semester. This finding was supported by longitudinal studies. For example, Tice and Baumeister, 1997; cited in Krispenz et al., 2019) found that procrastinating students report less anxiety than those without procrastination; they only experience anxiety at the beginning of the course or academic year. Yerdelen, McCaffrey \& Klassen (2016) also found that procrastinating students reported less anxiety over the same time with increasing procrastination. Procrastination seems to be a coping strategy in these students against anxiety and negative emotions.

Furthermore, some individuals are unable to identify their emotions and fail to adjust their emotions to manage anxious situations. Emotions directly influence thinking to facilitate decision-making, thinking, and action; accordingly, when experiencing negative emotions, they focus on more details and remember further errors. When experiencing positive excitement, they seek positive results and develop optimal performance (Emmerling, Shanwal \& Mandal, 2008). Emotion Regulation (ER) is defined as the process of initiating, maintaining, modifying, or changing the occurrence, intensity, or continuity of an inner feeling. Such feelings include the awareness and understanding of emotions, the ability to manage and accept emotions and to act according to the intended goals to achieve individual goals and situational demands. Individuals cope with the emotional distress using different strategies to regulate emotion; some of which are adaptive and others are maladaptive. Adaptive ER enables one to successfully function in the environment. Moreover, when faced with a problematic emotional experience, they could adopt behaviors along with their goals.

The maladaptive ER strategies, like trauma-related rumination, emerge shortly after exposure to the harmful situation. Thus, individuals' differences in using various Cognitive Emotion Regulation (CER) styles lead to different emotional, cognitive, and social consequences (Garnefski, Kraaij \& Spinhoven, 2001). The 9 CER strategies proposed by Garnefski et al. (2001) include self-blame, other blame, rumination, catastrophizing, acceptance, putting into perspective, positive refocusing, positive reappraisal, and refocus on planning. Studies revealed that students' anxiety and emotion can be predictable through their ER strategies, especially during exams (Capa-Aydin, Sungur \& Uzuntiryaki, 2009). Failure to successfully regulate emotions is the underlying mechanism of anxiety (Campbell-Sills \& Barlow, 2007). Moreover, some researchers believe that negative emotion is an essential antecedent to procrastination; therefore, ER is an effective function of procrastination.
In line with this, previous studies signified a negative significant relationship between adoptive ER strategies and procrastination (Ghasemi Jobaneh, Mousavi, Zanipoor \& Hoseini Seddigh, 2016; Gross, 2002; Berking \& Wupperman, 2012). Investigations on interventions affecting CER indicated that procrastination was reduced by ER skills training (Eckert, Ebert, Lehr, Sieland \& Berking, 2016). Anxiety is an antecedent that drives ER toward unconventional strategies and consequently increases academic procrastination. Numerous theories and research have elucidated this issue from a theoretical perspective (Grunschel, Schwinger, Steinmayr \& Fries, 2016); however, few studies directly examined this assumption.

Besides, in one of the causal explanations of procrastination, considering the subject or outcome of the assignment worthless, is the cause of procrastination (Chen $\&$ Han, 2017). The awareness of worthiness and commitment to the task is achieved through Mindfulness. Mindfulness indicates paying attention to the present in a specific, goal-oriented manner and without judging the internal and external experiences (Dudovitz, Li \& Chung, 2013). There exist several definitions for mindfulness; however, all definitions emphasize two key elements in mindfulness; direct attention to the present as well as openness and acceptance. Through mindfulness, the reality is perceived and becomes less distorted. Thus, events are processed in a real, negative, and unpleasant way, preventing over-estimation and impulsive emotions (Falkenström, 2010). Previous studies explored the effects of mindfulness on academic achievement and AP; with enhanced mindfulness, AP decreased and academic achievement increased (Mrazek et al., 2017).

The underlying premise of the association between mindfulness and AP is that mindfulness enables one to recognize and learn about their ability to experience positive emotions, coping, and mental events, positively. In other words, mindfulness, at the fundamental level, is a form of consciousness and awareness that prevents constant rumination as a useful coping style, leading to adaptability (Mettler, Carsley, Joly \& Heath, 2019). The essential mediating role of CER strategies in the relationship between mindfulness and AP is clear. Research results suggested that with increasing positive behavior and decreasing negative emotion, the behavior pattern changes, negative dysfunctional thoughts stop, and adaptation increases (Schroevers \& Brandsma, 2010).

CER was considered by numerous researchers in recent years, as a mediating variable (Taube-Schiff et al., 2015; Patron, Messerotti Benvenuti, Favretto, Gasparotto \& 
Palomba, 2014). The reason for this attention is to support the literature on the relationship between different types of ER strategies and their consequences; thus, adaptive CER strategies present protective and maladaptive effects (Grezellschak, Lincoln \& Westermann, 2015).

Education subject professionals seek to reduce AP in students by applying various research and motivational methods. According to the literature, data concerning the mediating role of CER strategies on the relationship between mindfulness, anxiety, and AP are scarce. Studies suggested that AP is affected by multiple complex relationships; however, most of these studies have only investigated one dimension of the relationship between academic achievement and other variables. Accordingly, they disregarded examining the mediating or effective roles of an intervention on such relationships. There exists no coherent structural model in this regard. Clarifying the mediating relationships in the form of structural relationships can help formulate effective programs to reduce AP. Therefore, the present study aimed to examine the structural relationships between mindfulness, anxiety, and AP with emphasis on examining the mediating role of CER strategies in female students.

\section{Materials and Methods}

This study is fundamental in terms of purpose and is a descriptive correlational one concerning the method. In this study, mindfulness and anxiety were considered as exogenous variables; AP was an endogenous variable, adaptive and maladaptive CER strategies were the mediating variables.

The statistical population of this study included all ( $n=800$ ) high school female students of Rasht City, Iran, in the academic year 2018-2019. The students were selected from 8 schools in Rasht. The sample size of the study was measured as 280 according to Krejcie and Morgan (1970) Table. They were selected using a twostage cluster sampling approach (first selecting schools, then the random clusters of classes from schools) and from different fields of study. However, to counteract sample dropout and incomplete data provision, 20\% dropout was considered and the final sample size was calculated to be 350 subjects. The inclusion criterion was 14-18 years of age. The exclusion criteria of the study were as follows: providing incomplete questionnaires; expressing dissatisfaction during the tests, and being unable to cooperate physically, mentally, or cognitively in the study. After obtaining informed consent forms under the conditions of anonymity and confidentiality of the information, and after providing a brief explanation of the tests and their completion, the study participants completed 3 questionnaires along with a demographic questionnaire in their classes. Research tools included the following:

\section{Academic Procrastination Scale (APS)}

This questionnaire was developed by Solomon and Rothblum (1984) and has 27 items that examine 3 components. The first component exams preparation and includes 8 items. The second component concerns preparation for homework and includes 11 items. The third component addresses preparation for the semester homework and includes 8 items. The items are scored based on a five-point Likert-type scale, ranging from 1 (never) to 5 (always) and some items are scored reversely. In Iran, Namiyan \& Hosen Chari (2011) obtained Cronbach's alpha coefficient of 0.73 for the reliability of this scale. In this study, a 27-item version of APS was used. The validity of the questionnaire in the study of Jokar \& Delavarpour (2007) was calculated to be satisfactory using the factor analysis method.

\section{The Five-Facet Mindfulness Questionnaire (FFMQ)}

This 39-item self-report scale was developed by Baer, Smith, Hopkins, Krietemeyer \& Toney (2006) using the factor analysis approach. The FFMQ is scored based on a Likert-type scale, ranging from 1 (never) to 5 (always). The researchers conducted an exploratory factor analysis on a sample of students and called the obtained factors as follows: observing, describing, acting with awareness, non-judging, and non-reactivity. Based on the collected results, the internal consistency of each factor was appropriate. Furthermore, Cronbach's alpha coefficient ranged from 0.75 (in non-reactivity factor) to 0.91 (in describing factor). In Iran, the FFMQ's test-retest correlation coefficients were calculated to range between $r=0.57$ (attributable to non-judging factor) and $\mathrm{r}=0.84$ (observing factor) (Ahmadvand, Heydarinasab \& Shairi, 2013). Dehghan Manshadi, Taghavi \& Dehghan Manshadi (2012) also reported the internal consistency of different dimensions of FFMQ (0.81-0.93).

\section{Cattell Anxiety Test (CAT) (Cattell, 1957)}

CAT has 40 questions with 3 options of Yes, No, and between the two and the subject has to choose one of the options. This test not only measures general anxiety, but also hidden (20 items) and manifest anxiety (20 items), as well as 5 primary personality factors, as follows: the lack of self-consciousness integration; the lack of solidarity or general neuroticism; paranoid insecurity; ten- 
dency to a sense of guilt, and erg-tension; each of which has its set of questions. The scoring method of this test is that in a set of questions, the answers yes, no, or between the two achieve 2, 0 , and 1 points, respectively. However, in the other set of questions, the answers yes, no, or between the two achieve 0,2 , and 1 points, respectively. In Iran, this test was standardized in 1989 by Dadsetan and Mansour among the Iranian subjects. IN total, 24894 people participated in this standardization. The validity of this test, which has been repeated numerous times has always been measured to be $>0.70$ (Corraze, 2002).

\section{Cognitive Emotion Regulation Questionnaire (CERQ):}

This questionnaire is a 36-item tool that describes CER strategies in response to life-threatening events based on a five-point Likert-type scale, ranging from 1 (never) to 5 (always) according to the following 9 subscales: self-blame, other-blame, rumination, and catastrophizing (these four components are called maladaptive CER strategies). Additionally, putting into perspective, positive refocusing, positive reappraisal, acceptance, and refocus on planning are the adaptive CER strategies. The minimum score of each component is 4 , the maximum score is 20 and higher indicate greater use of those cognitive regulation strategies (Garnefski \& Kraaij, 2006). The psychometric properties of the CERQ were confirmed in previous studies (Garnefski \& Kraaij, 2006; Garnefski et al., 2001). The Persian version of the 36item CERQ was standardized by Hasani (2010) in the Iranian population; accordingly, its reliability, based on Cronbach's alpha coefficient was obtained as 0.51-0.77. Besides, the validity of CERQ was reported by exploratory factor analysis with varimax rotation and correlation between subscales (ranging from 0.32 to 0.67 ); its optimal criterion validity was also reported.
In this study, Pearson's correlation coefficient and structural equation modeling technique were used to analyze the obtained data in SPSS and AMOS.

\section{Results}

The Mean \pm SD age of the explored students was $16.23 \pm 1.54$ years and they had studied for $11.28 \pm 1.23$ years. Data analysis was performed on 350 students. There were univariate and multivariate outliers in each data analysis, i.e., identified and excluded from the statistical processing by Box Plot and Mahalanobis distance test, respectively. Table 1 presents the statistical characteristics, including Mean \pm SD scores of the demographic features of the study subjects and the correlation coefficients of the main study variables.

As per Table 1, there was a direct and significant relationship between AP, anxiety, and maladaptive CER strategies $(\mathrm{P}<0.0001)$. There was a significant inverse relationship between AP, adaptive CER strategies, and mindfulness $(\mathrm{P}<0.0001)$. Moreover, the significance level of the Kolmogorov-Smirnov test in all variables was above 0.05 ; therefore, with $95 \%$ confidence, the distribution of variables' scores was normal.

The maximum likelihood method was used to evaluate the structural model and to fit it with the collected data. In this study, Mardia's normalized multivariate kurtosis value was employed to investigate the multivariate normality. This figure was equal to 82.03 in the present study, i.e., below 624, and calculated by the $p(p+2)$ formula. In this formula, $p$ equals the number of variables in the model, i.e., 24 in this study (Teo \& Noyes, 2014). The indices proposed by Gefen, Straub $\&$ Boudreau (2000) were used to determine the model fit. These indicators include $\chi^{2} / \mathrm{df}$ with acceptable values $<3$, Goodness of Fit Index (GFI), Adaptive Fit Index (CFI); values $>0.9$ indicate a good fit to the model,

Table 1. Pearson correlation coefficients matrix between latent, manifest anxiety, mindfulness skills, and academic procrastination in the explored adolescent girls

\begin{tabular}{|c|c|c|c|c|c|c|c|c|}
\hline Variables & Mean \pm SD & K-S z & $\mathbf{P}$ & 1 & 2 & 3 & 4 & 5 \\
\hline 1. Adaptive strategies & $67.32 \pm 16.92$ & 1.20 & 0.11 & - & $0.57^{* *}$ & $-0.18^{* *}$ & $0.16^{*}$ & $-0.20^{* *}$ \\
\hline 2. Non-Adaptive strategies & $116.00 \pm 12.56$ & 1.04 & 0.22 & & - & $0.54^{* *}$ & $-0.21^{* *}$ & $0.13^{* *}$ \\
\hline 3. Anxiety & $38.04 \pm 7.38$ & 1.16 & 0.29 & & & - & $-0.20^{* *}$ & $0.40^{* *}$ \\
\hline 4. Mindfulness & $118.72 \pm 12.92$ & 0.79 & 0.51 & & & & - & $-0.15^{*}$ \\
\hline 5. Academic procrastination & $74.88 \pm 13.11$ & 1.11 & 0.27 & & & & & - \\
\hline
\end{tabular}




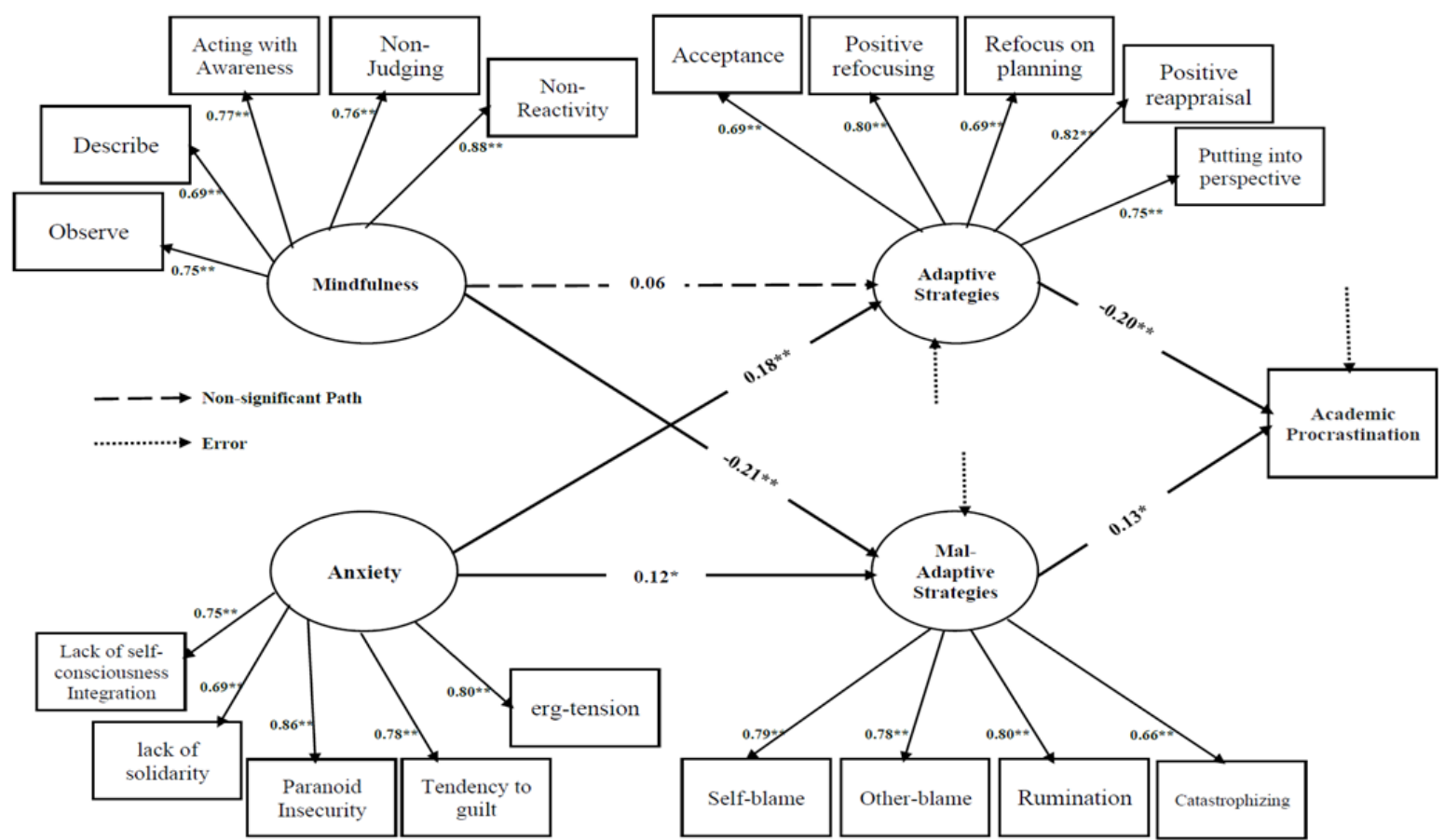

Chi-squared=1013.169, df=289, $\mathrm{P}=0.0001, \mathrm{RMSEA}=0.085$.

PRACTICE In CLINICAL PSYCH LOGY

Figure 1. Standardized coefficients of the proposed model of structural relationships between mindfulness, anxiety, and procrastination based on the mediating role of cognitive emotion regulation strategies

and Adjusted Goodness of Fit Index (AGFI) with values $>0.8$. The Parsimonious Normed Fit Index (PNFI) with the values $>0.6$ indicates a good model fit and the Root Mean Square Error of Approximation (RMSEA) with the values $<0.08$ indicates a good fit to the model. These indicators are reported in Table 2.
According to Table 2, the CFI, AGFI, GFI, and Normed Fit Index (NFI) were higher than the values presented by Gefen et al. (2000). The values of RMSEA and $\chi 2 /$ df were also lower than those mentioned above. Based on these findings, the tested model (after modifying \& deleting the procrastination vectors and incorporating

Table 2. The fitness of the proposed model to the obtained data based on the fit indices

\begin{tabular}{cc}
\hline Modification Indices & Tested Model \\
\hline$\chi^{2}$ & 1013.169 \\
df & 289 \\
\hline P & 0.0001 \\
\hline$X^{2} /$ df & 3.50 \\
Goodness of Fit Index (GFI) & 0.93 \\
Adjusted Goodness of Fit Index (AGFI) & 0.93 \\
Normed Fit Index (NFI) & 0.93 \\
Tucker-Lewis Index (TLI) & 0.79 \\
Comparative Fit Index (CFI) & 0.96 \\
\hline Root Mean Square Error of Approximation (RMSEA) & 0.085 \\
\hline
\end{tabular}


Table 3. Bootstrap analysis results in Preacher and Hayes (2008) macro program for indirect paths

\begin{tabular}{cccccccc}
\hline Paths & Values & Boot & Bias & SE & & \multicolumn{2}{c}{ 95\%Cl } \\
\cline { 5 - 7 } & & & & Lower & Upper \\
\hline Mindfulness $\rightarrow$ Adaptive CER $\rightarrow$ Procrastination & 0.0170 & 0.0174 & 0.0004 & 0.0163 & -0.0135 & 0.0505 \\
\hline Mindfulness $\rightarrow$ Non-adaptive CER $\rightarrow$ Procrastination & 0.0026 & 0.0023 & -0.0003 & 0.0165 & -0.0279 & 0.0384 \\
Anxiety $\rightarrow$ Adaptive CER $\rightarrow$ Procrastination & -0.1465 & -0.1444 & 0.0021 & 0.0602 & -0.2860 & -0.0448 \\
Anxiety $\rightarrow$ Non-adaptive CER $\rightarrow$ Procrastination & 0.3759 & 0.3724 & -0.0034 & 0.0885 & 0.2192 & 0.5673 \\
\hline
\end{tabular}

them in the model as the observed variable) presented a good fit. Figure 1 shows the final model with standard path coefficients.

As Figure 1 illustrates, the path of mindfulness to adaptive CER strategies $(\beta=0.06)$ was not significant $(\mathrm{P}>0.05)$. The path of anxiety to maladaptive CER strategies $(\beta=0.12)$ and the path of maladaptive CER strategies to procrastination $(\beta=0.13)$ was significant at $\mathrm{P}<0.05$. The rest of the paths in Figure 1 were significant at $\mathrm{P}<0.01$. There was also an underlying assumption of the structural pattern in the present study suggesting indirect or mediating pathways. Bootstrap analysis in Preacher \& Hayes (2008) Macro program in SPSS was used to determine the significance of each mediating relationship and the indirect effects of the independent variable on the dependent variable by the mediator variable. The Bootstrap results for the mediating paths of the proposed model are in Table 3.

Table 3 indicates the significance of mediating anxiety pathways to AP through adaptive and maladaptive CER strategies. The confidence interval equaled 0.95 and the bootstrap re-sampling number was 5000. Given that zero is outside this confidence interval, these mediating relationships were significant. The rest of mediating relationships, in which there was an exogenous variable of mindfulness, were not significant.

\section{Discussion}

The present study aimed to investigate the structural relationships between mindfulness and anxiety with the mediating role of CER strategies on AP in female students. The initial results provided a direct relationship between AP, anxiety, and maladaptive CER strategies. Besides, there was a reverse and significant relationship between AP, adaptive CER strategies, and mindfulness. This result was in line with those of others, such as
Afshari \& Hashemi (2019), Ekert et al. (2016), Habibi (2020), Yaghobi, Ghalaei, Rashid \& Korde Nughabi, (2015), as well as Ghasemi Jobaneh et al. (2016). Procrastination is a cognitive problem and there was a significant relationship between this issue and positive cognitive constructs -mindfulness- and a negative element, anxiety.

According to theorists, mindfulness is significantly associated with reduced procrastination. This is achieved by increased self-control and eliminated loop of negative and crippling thoughts in the impaired cycle of motivation and action (Howell \& Buro, 2011). A form of cognitive anxiety to negative self-evaluation and selfesteem, compared to others and insecurity leads to the adoption of maladaptive CER strategies, such as self- or other-blame, or catastrophizing by losing strength and perseverance; accordingly, it expands the gap between the intention and action and the cause of procrastination.

The results of structural equation modeling and Bootstrap analysis revealed that maladaptive CER strategies mediated the relationship between anxiety and AP. In other words, maladaptive strategies exacerbate the effect of anxiety on AP. Maladaptive CER strategies are more likely to increase their anxiety than AP. In other words, students with higher levels of maladaptive CER strategies are more prone to experience greater anxiety. This finding was consistent with those of other studies, such as Krispenz et al. (2019), Gharibnavaz, Nouri Ghasem Abadi \& Moghadasin (2018), and Haghshenas, Nouri, Moradi \& Sarami (2014). The direct and mediating effects of maladaptive CER strategies on the relationship between anxiety and AP indicate that individuals who cannot manage and control daily negative events experience longer confusion and develop specific anxieties, consequently. Moreover, the mediating role of CER strategies between anxiety and AP was significant; thus, students who moderated and controlled the anxiety expe- 
rience by adaptive CER strategies presented less procrastination. This result was partly consistent with those of previous studies (Capa-Aydin et al., 2009; Sirois \& Tosti, 2012). The mediating role of maladaptive CER strategies was significant, compared to the mediating role of CER adaptive strategies. Aldao \& Nolen-Hoeksema (2010) as well as Garnefski \& Kraaij (2006) agreed that effective and adaptive CER strategies play a minor role in CER, compared to the dysfunctional strategies, such as rumination, self- or other-blame, or catastrophizing on CER. Campbell-Sills \& Barlow (2007) signified maladaptive CER strategies as the underlying mechanisms of anxiety; therefore, there exist intensifying and crippling relationships between the two. The present results were consistent with those of previous investigations (Mettler et al., 2019; Porparizi, Towhidi \& Khezri Moghadam, 2018) concerning the significance of the mediating role of adaptive mindfulness strategies and procrastination versus the inverse and significant relationship of mindfulness and procrastination. Accordingly, mindfulness could help individuals to become less entrapped in procrastination with present-based conscious judgment and increased concentration. In other words, it can reduce procrastination by activating adaptive CER strategies, such as refocusing and re-evaluating.

The present study was associated with such limitations, as restricting the sample to the female gender, one educational level, and Rasht City (Northern Iran); thus, caution is required in data generalization. The research design was descriptive and correlational and the measurements were performed using self-reported questionnaires, which prevent causal inferences and comprehensive evaluation. Therefore, the researchers suggest considering male student samples of different educational levels in other cities and using non-descriptive designs and multi-faceted interviews, observation, and self-report questionnaires in future studies.

Given the emphasis and purpose of the present study on the mediating role of CER strategies in the relationship between anxiety and AP in female students, it is recommended to the educators, therapists, and parents that while examining CER strategies in students, assist them to reduce AP by delivering group- and individual-based training courses to them. Besides, identifying and correcting maladaptive CER strategies and learning and reinforcing adaptive CER strategies by preventing the destructive effects of anxiety on AP are suggested in students.

\section{Conclusion}

Procrastination in students could be reduced by minimizing anxiety, correcting maladaptive CER strategies, and strengthening adaptive CER strategies. Anxiety may aggravate AP by generating maladaptive mechanisms.

\section{Ethical Considerations}

\section{Compliance with ethical guidelines}

All the study procedures complied with the ethical guidelines of the Declaration of Helsinki (2013).

\section{Funding}

This research did not receive any grant from funding agencies in the public, commercial, or non-profit sectors.

\section{Authors' contributions}

Conceptualization, Methodology, Data collection, Data analysis, and Supervision: Sajjad Rezaei; Investigation, Writing-original Draft, and Writing review and editing: Azra Zebardast.

\section{Conflict of interest}

The authors declared no conflicts of interest.

\section{Acknowledgments}

The researchers appreciate the cooperation of all principals, assistants, and high school students in the sampled schools in Rasht who contributed to this study.

\section{References}

Afshari, A., \& Hashemi, Z. (2019). [The relationship between anxiety sensitivity and metacognitive beliefs and test anxiety among students (Persian)]. Journal of School Psychology, 8(1), 7-25. http://jsp.uma.ac.ir/article_793.html

Ahmadvand, Z., Heydarinasab, L., \& Shairi, M. R. (2013). [An investigation of the validity and reliability of psychometric characteristics of five facet mindfulness questionnaire in Iranian non-clinical samples (Persian)]. International Journal of Behavioral Sciences, 7(3), 229-37. http://www.behavsci.ir/ article 67834.html

Aldao, A., \& Nolen-Hoeksema, S. (2010). Specificity of cognitive emotion regulation strategies: A transdiagnostic examination. Behavior Research and Therapy, 48(10), 974-83. [DOI:10.1016/j. brat.2010.06.002] [PMID] 
Baer, R. A., Smith, G. T., Hopkins, J., Krietemeyer, J., \& Toney, L. (2006). Using self-report assessment methods to explore facets of mindfulness. Assessment, 13(1), 27-45. [DOI:10.1177/1073191105283504] [PMID]

Berking, M., \& Wupperman, P. (2012). Emotion regulation and mental health: Recent findings, current challenges, and future directions. Current Opinion in Psychiatry, 25(2), 128-34. [DOI:10.1097/YCO.0b013e3283503669] [PMID]

Campbell-Sills, L., \& Barlow, D. H. (2007). Incorporating emotion regulation into conceptualizations and treatments of anxiety and mood disorders. In J. J. Gross (Ed.), Handbook of emotion regulation (pp. 542-559). New York: Guilford Press. https:/ / books.google.com/books?id=Jh811ZKqFH8C\&dq

Capa-Aydin, Y., Sungur, S., \& Uzuntiryaki, E. (2009) Teacher self-regulation: Examining a multidementional construct. Educational Psychology, 29(3), 345-56. [DOI:10.1080/01443410902927825]

Cattell, R. B. (1957). Handbook for the IPAT anxiety scale (self analysis form): Brief, verbal, questionnaire, Q-form, as distinct from objective T-battery. Champaign: Institute for Personality and Ability Testing. https://books.google.com/ books?id=6VjrtgAACAAJ\&dq

Chang, H. K. (2014). Perfectionism, anxiety and academic procrastination: The role of intrinsic and extrinsic motivation in college students. [MSc. thesis]. San Bernardino: California State University. http://scholarworks.lib.csusb.edu/etd/28/

Chen, B. B., \& Han, W. (2017). Ecological assets and academic procrastination among adolescents: The mediating role of commitment to learning. Frontiers in Psychology, 8, 1971. [DOI:10.3389/fpsyg.2017.01971] [PMID] [PMCID]

Corraze, J. (2002). An outline of General Psychopathology (Mental Diseases). M. Mansour and P. Dadsetan, Persian Trans. Tehran: Roshd Publication. http://opac.nlai.ir/opac-prod/bibliographic/635195

Dehghan Manshadi, Z., Taghavi, S. M. R., \& Dehghan Manshadi, M. (2012). [Psychometric characteristics of the Kentucky inventory of mindfulness skills (Persian)]. Thoughts and Behavior in Clinical Psychology, 7(25), 27-36. https://www.sid.ir/fa/ journal/ViewPaper.aspx?ID=215342

Dudovitz, R. N., Li, N., \& Chung, P. J. (2013). Behavioral self-concept as predictor of teen drinking behaviors. Academic Pediatrics, 13(4), 316-21. [DOI:10.1016/j.acap.2013.03.005] [PMID]

Eckert, M., Ebert, D. D., Lehr, D., Sieland, B., \& Berking, M (2016). Overcome procrastination: Enhancing emotion regulation skills reduce procrastination. Learning and Individual Differences, 52, 10-8. [DOI:10.1016/j.lindif.2016.10.001]

Emmerling, R. J., Shanwal, V. K., \& Mandal, M. K., Eds. (2008). Emotional intelligence: Theoretical and cultural perspective. New York: Nova Science Publishers, Inc. https://books.google. com/books?id=TJF5892APCoC\&dq

Falkenström, F. (2010). Studying mindfulness in experienced meditators: A quasi-experimental approach. Personality and Individual Differences, 48(3), 305-10. [DOI:10.1016/j.paid.2009.10.022]

Ferrari, J. R. (2000). Procrastination and attention: Factor analysis of attention deficit, boredomness, intelligence, selfesteem, and task delay frequencies. Journal of Social Behavior $\mathcal{E}$ Personality, 15(5), 185-96. https://psycnet.apa.org/record/2002-10572-014
Garnefski, N., \& Kraaij, V. (2006). Cognitive emotion regulation questionnaire-development of a short 18 -item version (CERQ-short). Personality and Individual Differences, 41(6), 1045-53. [DOI:10.1016/j.paid.2006.04.010]

Garnefski, N., Kraaij, V., \& Spinhoven, P. (2001). Negative life events, cognitive emotion regulation and emotional problems. Personality and Individual Differences, 30(8), 1311-27. [DOI:10.1016/S0191-8869(00)00113-6]

Gefen, D., Straub, D., \& Boudreau, M. C. (2000). Structural equation modeling and regression: Guidelines for research practice. Communications of the Association for Information Systems, 4, 7. [DOI:10.17705/1CAIS.00407]

Gharibnavaz, S., Nouri Ghasem Abadi, R., \& Moghadsian, M. (2018). [Relationship between metacognition believes and exam anxiety: Mediating role of cognitive emotion regulation (Persian)]. Journal of Cognitive Psychology, 5(4), 1-10. http:// jcp.khu.ac.ir/article-1-2843-fa.html

Ghasemi Jobaneh, R., Mousavi, S. V., Zanipoor, A., \& Hosein Seddigh, M. A. (2016). [The relationship between mindfulness and emotion regulation with academic procrastination of students (Persian)]. Education Strategies in Medical Sciences, 9(2), 134-41. http://edcbmj.ir/article-1-970-en.html

Grezellschak, S., Lincoln, T. M., \& Westermann, S. (2015). Cognitive emotion regulation in patients with schizophrenia: Evidence for effective reappraisal and distraction. Psychiatry Research, 229(1-2), 434-9. [DOI:10.1016/j.psychres.2015.05.103] [PMID]

Gross, J. J. (2002). Emotion regulation: Affective, cognitive, and social consequences. Psychophysiology, 39(3), 281-91. [DOI:10.1017/S0048577201393198] [PMID]

Grunschel, C., Schwinger, M., Steinmayr, R., \& Fries, S. (2016) Effects of using motivational regulation strategies on students' academic procrastination, academic performance and well-being. Learning and Individual Differences, 49, 162-70. [DOI:10.1016/j.lindif.2016.06.008]

Habibi, M. H. (2020). [The effectiveness of mindfulness-based stress reduction program on academic procrastination and academic motivation of female students (Persian)]. Rooyeshe-Ravanshenasi Journal, 8(11), 57-66. http:/ / frooyesh.ir/article1-1615-fa.htm

Haghshenas, Z., Nouri, R., Moradi, A. R., \& Sarami, Gh. R. (2014). [Evaluation of coping styles, metacognition and its relationship with test anxiety in Tehran Teacher Training University (Persian)]. Journal of Mazandaran University of Medical Sciences, 23(1), 145-55. http://jmums.mazums.ac.ir/article1-3448-en.html

Hasani, J. (2010). [The psychometric properties of the Cognitive Emotion Regulation Questionnaire (CERQ) (Persian)]. Journal of Clinical Psycology, 2(3), 73-84. [DOI:10.22075/JCP.2017.2031]

Howell, A. J., \& Buro, K. (2011). Relations among mindfulness, achievement-related self-regulation, and achievement emotions. Journal of Happiness Studies, 12(6), 1007-22. [DOI:10.1007/ s10902-010-9241-7]

Hussain, I., \& Sultan, S. (2010). Analysis of procrastination among university students. Procedia - Social and Behavioral Sciences, 5, 1897-904. [DOI:10.1016/j.sbspro.2010.07.385]

Jokar, B., \& Delavarpour, M. A. (2007). [The relationship between Academic procrastination and goal achievement (Per- 
sian)]. The Journal of New Thoughts on Education, 3(3), 61-80. [DOI:10.22051/JONTOE.2007.312]

Krejcie, R. V., \& Morgan, D. W. (1970). Table for determining sample size from a given population. Educational and Psychological Measurement, 30(3), 607-10. [DOI:10.1177/001316447003000308]

Krispenz, A., Gort, C., Schültke, L., \& Dickhäuser, O. (2019). How to reduce test anxiety and academic procrastination through inquiry of cognitive appraisals: A pilot study investigating the role of academic self-efficacy. Frontiers in Psychology, 10, 1917. [DOI:10.3389/fpsyg.2019.01917] [PMID] [PMCID]

Lazarus, R. S., \& Folkman, S. (1984). Stress, appraisal and coping. New York: Springer. https:// books.google.com/books?id=iySQQuUpr8C\&dq

Mettler, J., Carsley, D., Joly, M., \& Heath, N. L. (2019). Dispositional mindfulness and adjustment to university. Journal of College Student Retention: Research, Theory \& Practice, 21(1) 3852. [DOI:10.1177/1521025116688905]

Mrazek, M. D., Zedelius, C. M., Gross, M. E., Mrazek, A. J., Phillips, D. T., \& Schooler, J. W. (2017). Mindfulness in education: Enhancing academic achievement and student well-being by reducing mind-wandering. In J. C. Karremans, \& E. K. Papies (Eds.), Mindfulness in social psychology (pp. 139-152). London: Routledge. [DOI:10.4324/9781315627700-10]

Namiyan, S., \& Hosen Chari, M. (2011). [Explaining academic procrastination in university students based on locus of control and religious beliefs (Persian)]. Journal of Educational Psychology Studies, 8(14), 99-128. [DOI:10.22111/JEPS.2012.705]

Patron, E., Messerotti Benvenuti, S., Favretto, G., Gasparotto, R., \& Palomba, D. (2014). Depression and reduced heart rate variability after cardiac surgery: The mediating role of emotion regulation. Autonomic Neuroscience: Basic \& Clinical, 180, 53-8. [DOI:10.1016/j.autneu.2013.11.004] [PMID]

Pekrun, R., Frenzel, A. C., Goetz, T., \& Perry, R. P. (2007). The control-value theory of achievement emotions: An integrative approach to emotions in education. In P. A. Schutz, \& R. Pekrun (Eds.), Emotion in education: Educational psychology (pp. 13-36). Cambridge, MA: Academic Press. [DOI:10.1016/B978012372545-5/50003-4]

Porparizi, M., Towhidi, A., \& Khezri Moghadam, N. (2018). [The effect of mindfulness on academic achievement, and academic adjustment: The mediation role of academic selfconcept (Persian)]. Positive Psychology Research, 4(3), 29-44. [DOI:10.22108/PPLS.2018.111795.1464]

Preacher, K. J., \& Hayes, A. F. (2008). Asymptotic and resampling strategies for assessing and comparing indirect effects in multiple mediator models. Behavior Research Methods, 40(3), 879-91. [DOI:10.3758/BRM.40.3.879] [PMID]

Putwain, D. W., \& Daniels, R. A. (2010). Is the relationship between competence beliefs and test anxiety influenced by goal orientation? Learning and Individual Differences, 20(1), 8-13. [DOI:10.1016/j.lindif.2009.10.006]

Schroevers, M. J., \& Brandsma, R. (2010). Is learning mindfulness associated with improved affect after mindfulness-based cognitive therapy? British Journal of Psychology, 101(1), 95-107. [DOI:10.1348/000712609X424195] [PMID]

Sirois, F. M., \& Tosti, N. (2012). Lost in the moment? An investigation of procrastination, mindfulness, and well-being. Jour- nal of Rational-Emotive E Cognitive-Behavior Therapy, 30(4), 23748. [DOI:10.1007/s10942-012-0151-y]

Solomon, L. J., \& Rothblum, E. D. (1984). Academic procrastination: Frequency and cognitive-behavioral correlates. Journal of Counseling Psychology, 31(4), 503-9. [DOI:10.1037/00220167.31.4.503]

Taube-Schiff, M., Van Exan, J., Tanaka, R., Wnuk, S., Hawa, R., \& Sockalingam, S. (2015). Attachment style and emotional eating in bariatric surgery candidates: The mediating role of difficulties in emotion regulation. Eating Behaviors, 18, 36-40. [DOI:10.1016/j.eatbeh.2015.03.011] [PMID]

Teo, T., \& Noyes, J. (2014). Explaining the intention to use technology among pre-service teachers: A multi-group analysis of the unified theory of acceptance and use of technology. Interactive Learning Environments, 22(1), 51-66. [DOI:10.1080/10 494820.2011.641674

Tice, D. M., \& Baumeister, R. F. (1997). Longitudinal study of procrastination, performance, stress, and health: The costs and benefits of dawdling. Psychological Science, 8(6), 454-8. [DOI:10.1111/j.1467-9280.1997.tb00460.x]

Yaghobi, A., Ghalaei, B., Rashid, Kh., \& Korde Nughabi, R (2015). [Factors associated with academic procrastination (Persian)]. Quarterly Educational Psychology, 11(37), 161-85. https://www.sid.ir/fa/journal/ViewPaper.aspx?id=302638

Yerdelen, S., McCaffrey, A., \& Klassen, R. M. (2016). Longitudinal examination of procrastination and anxiety, and their relation to self-efficacy for self-regulated learning: Latent growth curve modeling. Educational Sciences: Theory \& Practice, 16(1) 5-22. [DOI:10.12738/estp.2016.1.0108]

Young, K. (2010). Internet addiction over the decade: A personal look back. World Psychiatry, 9(2), 91. [DOI:10.1002/j.2051-5545.2010.tb00279.x] [PMID] [PMCID] 